\title{
Sexualidad y reconocimiento como apuestas a la transformación de la seguritización en El Salvador: una reflexión transracional
}

Sexualidade e reconhecimento como apostas para a transformação da segurança em El Salvador: uma reflexão transracional

Sexuality and recognition as bets for the transformation of security in $\mathrm{El}$ Salvador: a transrational reflection

\section{Josefina Echavarría Alvarez}

- Doctora en Paz, Conflictos y Democracia de la Universidad Jaume I.

- $\quad$ Profesora Senior en la Unidad para Estudios de Paz y Conflictos y Directora de InnPeace - Centro de Investigación de Paz y Conflictos - de la Universidad de Innsbruck.

- $\quad$ Profesora invitada a varios centros, incluyendo las universidades Javeriana de Cali y de Antioquia, en Colombia, la Universidad Nacional de Ruanda y la Universidad Friedrich-Schiller en Jena, Alemania.

- $\quad$ Autora de In/Seguridad en Colombia: escribiendo las identidades políticas en la política de Seguridad Democrática (2010).

- $\quad$ Editora de las series "Masters of Peace" e "Investigaciones: Forschungen zu Lateinamerika".

- $\quad$ Coeditora del Manual internacional Palgrave de estudios de paz: una perspectiva cultural y de Resonancias transracionales: ecos a las muchas paces.

- josefina.echavarria@uibk.ac.at

- $\quad$ Doctoranda del Programa de Estudios Internacionales de Medio Ambiente y Desarrollo de la Universidad Noruega de Ciencias de la Vida.

- Maestría en el programa Paz, Desarrollo, Seguridad y Transformación de Conflictos Internacionales.

- $\quad$ Especialista en Estudios de la Paz y Transformación de Conflictos por la Escuela Aman de Estudios para la Paz y Transformación de Conflictos.

- Especialista en Construcción de la Paz y Transformación de Conflictos por la School for International Training.

- $\quad$ erika.rojas@nmbu.no 


\section{Resumen}

El reconocimiento de la diversidad sexual y de género es indispensable para contribuir a la construcción de la paz y a la transformación de conflictos en toda sociedad, aún más en la posguerra en El Salvador. Este ensayo mapea el caso de violencia contra mujeres trans en San Luis Talpa, ofreciendo un análisis elicitivo que visibiliza las profundas relaciones de género y sexualidad que subyacen a la reproducción de la violencia en la seguridad moderna.

PALABRAS CLAVE: PAZ TRANSRACIONAL・MAPEO DE CONFLICTOS • TRANSFORMACIÓN ELICITIVA• EL SALVADOR • DIVERSIDADES SEXUALES Y DE GÉNERO.

\section{Abstract}

The recognition of sexual diversity and gender is essential to contribute to peacebuilding and conflict transformation in society as a whole, especially in the postwar society of El Salvador. This essay maps cases of violence against transgender women in San Luis Talpa and offers an elicitive analysis that depicts the deep gender relations and sexuality that hide the reproduction of violence in modern security.

KEYWORDS: TRANSRACIAL PEACE • ELICITIVE CONFLICT MAPPING • ELICITIVE CONFLICT TRANSFORMATION • EL SALVADOR • SEXUAL AND GENDER DIVERSITY.

\section{Resumo}

O reconhecimento da diversidade sexual e de gênero é indispensável para contribuir com a construção da paz e da transformação de conflitos em toda a sociedade, principalmente na sociedade pós-guerra em El Salvador. Este ensaio traça um mapa sobre 0 caso de violência contra mulheres trans em San Luis Talpa e oferece uma análise elicitiva que visibiliza as profundas relações de gênero e sexualidade que dissimulam a reprodução da violência na moderna segurança. 


\section{INTRODUCCIÓN}

$\mathrm{E}$

Salvador es uno de los países no-en-guerra más violentos del mundo. La tasa de homicidios es considerada epidémica aun cuando ha disminuido de 104 homicidios por cada 100000 habitantes en 2015 a 60 en 2017 (Clavel, 2018). La violencia y los altos niveles de impunidad parecen un triste legado de la guerra civil que por 12 años aterrorizó a los pobladores de este país, hasta su conclusión en 1992. Sin embargo, para la posguerra no se propuso la transformación colectiva de los ciclos de violencia, la creación de memoria o la promoción de culturas no-violentas (Velásquez Estrada, 2015). En cambio, se impuso el indulto, el olvido, y se legitimó el uso de la violencia estatal a partir de medidas represivas de seguridad.

Los enfoques de seguridad en la postguerra han reproducido una división pública/privada de las expresiones de violencia, que obedece a una construcción jerárquica, androcéntrica y patriarcal de los géneros y de las relaciones de poder en la sociedad (Hume, 2008). De esta manera, la narrativa pública de seguridad sólo se centra en las tasas de homicidios, predominantemente de hombres, como la medida de los niveles de violencia de la sociedad (Zulver, 2016, p. 172). Esta narrativa falla en reflejar los impactos diferenciados que la violencia tiene en mujeres, en hombres periféricos y en otras expresiones de género, eliminando del debate público e inscribiendo en el ámbito privado formas de violencia asociadas al género (Red Feminista Frente a la Violencia contra las Mujeres, 2016). Como consecuencia, las políticas públicas en materia de seguridad se enfocan en la reducción de la criminalidad como bastión de lucha contra la violencia, y se olvidan de las condiciones socioeconómicas de la población y de otras formas de violencia que no se expresan, necesariamente, en el lenguaje de la criminalidad. Se da prioridad, entonces, a las prácticas represivas policiales hombre-céntricas (concentradas en problemas de ciertos hombres), hombre-genéricas (sin reconocer las vulnerabilidades de ciertos grupos de hombres) y hombre-estáticas (asumiendo que los hombres no cambian) (Barker; Greene, 2011, p. 24-27). Paradójicamente, las cifras de violencias y las políticas represivas dicen no estar "generadas", es decir, se presentan como "neutrales". Esta paradoja está en el corazón de las inefectividades de las políticas represivas mismas, puesto que al no reconocer el carácter "generado" de su propio enfoque, las diferentes violencias "generadas" no pueden ser adecuadamente enfrentadas y desarticuladas.

Utilizamos el caso San Luis Talpa como ejemplo para exponer la necesidad de considerar el género y la sexualidad para un análisis efectivo y completo de la transformación de conflictos, con el ánimo de disminuir la violencia. En la noche del 18 de febrero del 2017, Yasuni Orellana y Daniela Rodríguez fueron asesinadas mientras salían de una fiesta en San Luis Talpa, municipio en el departamento de La Paz, en El Salvador. Dos días después, el cuerpo de Elisa Castillo, presuntamente secuestrada después de asistir al entierro de Yasuni y Daniela, fue encontrado en la antigua carretera que lleva a la capital del departamento. Yasuni, Daniela y Elisa eran mujeres transexuales, o trans, como se conoce a las personas que han transformado su apariencia física y biológica para adecuarse al género con el que se identifican psicológica, espiritual y socialmente (Programa de las Naciones Unidas para el Desarrollo, 2015). ${ }^{2}$ La Fiscalía reportó los hechos criminales como "el asesinato de hombres vestidos de mujer".

El caso San Luis Talpa pudo haber sido silenciado entre tantas noticias de homicidios, pero estuvo presente en la opinión pública por el hecho de poner en la arena de discusión los crímenes de odio perpetrados en contra de las diversas expresiones

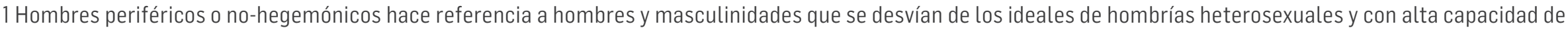

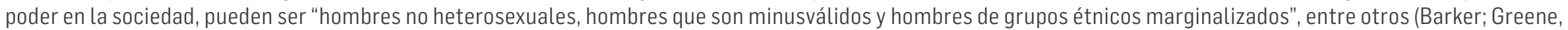
2010, p. 36).

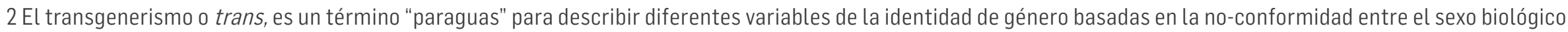

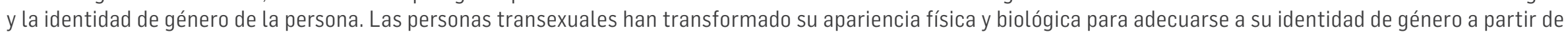

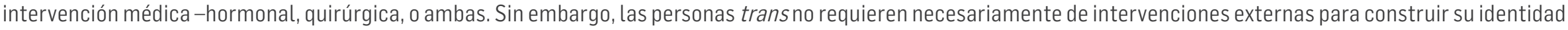
de género (Programa de las Naciones Unidas para el Desarrollo, 2015, p. 111).
} 
sexuales y de géneros. El hecho de que no fueron catalogados como "crímenes pasionales", como pasa en la mayoría de los casos de asesinatos de personas LGBTI, sino como "el asesinato de hombres vestidos de mujer", abrió especialmente el debate sobre el reconocimiento a la identidad de las personas trans, y los diferentes tipos de violencia que sufre esta población dentro de la ya reconocida violencia feminicida. Adicionalmente, puso el dedo en la llaga sobre el contexto de impunidad que ronda los crímenes de esta naturaleza.

El caso fue condenado por diversos grupos de defensa de derechos humanos de la población LGBTI en El Salvador y otros países Centro Americanos, y por la Comisión Interamericana de Derechos Humanos (CIDH), quienes increparon al Estado, especialmente a la Procuraduría de Derechos Humanos de El Salvador (PDDH), por su silencio. Adicionalmente, interpelaron a la justicia salvadoreña por no aplicar la reforma del artículo 129 del Código Procesal Penal, en donde se mandata la investigación y sanción de crímenes de intolerancia y odio cometidos en contra de expresiones e identidades diversas de sexualidad y género.

El 27 de Julio, la Policía, como parte de un operativo ordenado por la Fiscalía, capturó a ocho pandilleros en San Luis Talpa por el asesinato de dos de las tres mujeres trans. El tercer caso aún está indeterminado. Aun así, hasta ahora no hay personas que hayan sido condenadas por crímenes de odio. Tampoco ha disminuido la violencia contra esta población.

Más allá de la violencia física que sufrieron las mujeres trans en este caso, hay también violencia estructural y cultural asociada a la falta de reconocimiento de la identidad de género o sexual, que resulta en discriminación y violencia social y política. De acuerdo con la defensora de derechos LGBTI, Karla Avelar, la falta de reconocimiento legal de su identidad limita la ciudadanía de las personas trans y el goce de sus derechos, dificultando así el acceso a educación, salud, trabajo, vivienda, servicios bancarios, sufragio, y movilidad (La raíz..., 2017, pt. 2:27-3:33). Así mismo, durante un grupo focal organizado con mujeres trans en San Salvador, fue recurrente escuchar en sus narrativas que el rechazo cultural genera inestabilidad social y marginación, que las lleva a ser abandonadas o a alejarse de sus familias desde una temprana edad, y a vivir en la calle ejerciendo el trabajo sexual como una forma de sobrevivencia.

Según el Informe sobre la Situación de Derechos Humanos de las Mujeres Trans en El Salvador, el 85\% de las mujeres trans ejerce o ha ejercido el trabajo sexual como medio de subsistencia y tienen en promedio ingresos económicos por debajo de US\$180 al mes, ${ }^{3}$ y menos del 5\% trabaja en el sector privado. Muchas de estas mujeres reconocen que se le ha negado trabajo debido a su expresión de género. Adicionalmente, el hostigamiento, la estigmatización, la violencia y la exclusión también los experimentan en la educación, generando altos niveles de deserción escolar, llevando sólo al 36\% de las mujeres trans a terminar la educación secundaria (bachillerato) (Programa de las Naciones Unidas para el Desarrollo, 2015, p. 28-30). Adicionalmente, debido a los riesgos asociados a su situación socioeconómica y legal, su expectativa de vida es de 35 años en Centro América (Comisión Interaméricana de Derechos Humanos 2015, p. 15) y 33 años en El Salvador, de acuerdo con los datos de las organizaciones trans salvadoreñas.

De la mano de la invisibilidad de género de los datos, en El Salvador estos fenómenos de violencia se han enmarcado dentro de un discurso de seguritización. La seguritización hace referencia al movimiento de tomar asuntos conflictivos de ámbitos discursivos de políticas democráticas ordinarias, como pueden ser los ámbitos económicos, políticos, ambientales y sociales, para insertarlos dentro de la lógica de la seguridad del Estado. Este movimiento tiene una serie de condiciones y consecuencias bastante negativas para la transformación de conflictos, puesto que una vez que ciertos fenómenos se consideran "cuestiones de seguridad" para el Estado -y por lo tanto de interés nacional- dejan de estar bajo el escrutinio

3 Las cifras presentadas son del año 2015. En este año el salario mínimo de referencia en el área urbana era de USD\$251.70, y el valor de la canasta básica alimentaria era de USD\$133.51. Para más información, véase Observatorio del Derecho Humano a la Alimentación en Centroamérica (2014). 
público, se aducen secretos y razones de Estado que están más allá del debate político y, por lo tanto, se hace inherente un trato no-democrático del asunto en que fácilmente se justifica la violencia estatal (Echavarría, 2010, 2014).

El reacomodamiento de estos crímenes sexuales en El Salvador a lo largo de los discursos de seguridad estatal y nacional asimismo ha hecho que la vida de las personas que mueren a causa de la violencia se haya cosificado, y sus contextos socioeconómicos, se hayan invisibilizado y se utilizan para justificar la necesidad de continuar librando la guerra contra las pandillas. De lo anterior se desprende que la resolución de conflictos que se intenta con la seguritización de la violencia desgenerada se concentra en "solucionar" casos específicos, parar la violencia que amenaza la supervivencia estatal y castigar a los culpables individuales, sin preocuparse por el trasfondo en las dimensiones personales, estructurales, relacionales y culturales que alimentan y nutren las conflictividades que observamos. De allí que la resolución de conflictos dentro de un marco de seguritización sea de horizontes y profundidad limitadas.

Contraria a esta mirada de resolución, en los estudios de paz encontramos propuestas teóricas y prácticas de transformación elicitivas, es decir, transformaciones que se evocan, se proponen y se construyen con las personas directamente involucradas en los conflictos, y que les apuntan a cambios en los trasfondos violentos, incluyendo las maneras en que los géneros y las sexualidades anclan y, a su vez, se reproducen en las aristas violentas. En las aproximaciones elicitivas no sólo nos interesa tratar los temas o episodios conflictivos que requieren una resolución (por ejemplo, parar la violencia personal y relacional en un momento específico), sino que buscamos trabajar en capas más profundas de los conflictos, donde añoramos transformar el epicentro de la conflictividad. Mientras que el episodio es la expresión más visible de un conflicto, el epicentro "es la red de patrones relacionales, a menudo suministrando una historia de un episodio vivido, desde el cual emergen nuevos episodios y asuntos" (Lederach, 2003, p.31). En otras palabras, nos interesa entrever y transformar las relaciones que crean patrones que, a su vez, crean las estructuras e instituciones entendidas como la materialización de los patrones (Diamond, 1997, p. 46). Si efectivamente enfocamos el análisis y la transformación de los conflictos en el epicentro, vemos que aquello que sale a la superficie (que se puede ver y medir) sólo es la punta del iceberg de la conflictividad más profunda (Lederach; Neufeldt; Culbertson, 2007, p. 18).

En el particular caso de El Salvador, nos preguntamos entonces: ¿Qué revela el asesinato de tres mujeres trans sobre la sexualidad y el género en el epicentro de las violencias seguritizadas en El Salvador?A Apuntamos así al entramado de relaciones humanas en esta sociedad que no se tejen únicamente a partir de las violencias, sino también de las paces, de las muchas, diversas y plurales nociones de convivencia pacífica. Consideramos que una posible salida a la miopía seguritizada y resolutiva puede ser visibilizar las profundas relaciones de género y sexualidad que subyacen en la reproducción de la violencia.

\section{MARCO TEÓRICO}

Como mencionamos en la introducción, buscamos comprender los conflictos desde un ángulo alternativo, que procederemos a explicar adelante. Se trata de una apuesta conceptual, práctica y pedagógica de la Escuela de Paz de Innsbruck, donde se reúnen el Programa de Maestría y la Cátedra UNESCO en Estudios de Paz de la Universidad de Innsbruck, en Austria. El pensamiento de la Escuela ha estado liderado por Wolfgang Dietrich, para quien la investigación para la paz no se trata simplemente de anunciar que la paz es pensada, vista, imaginada y vivida de manera heterogénea, sino defiende que la investigación para la paz debe ir más allá y ocuparse de mostrar cómo se viven las diferentes paces a lo largo de la historia y en diversos contextos culturales, cómo se relacionan entre sí las diferentes nociones de paz y estudiar sus implicaciones para la transformación práctica de conflictos.

Al respecto, Wolfgang Dietrich (2012) dice que encuentra cinco categorías o familias distintivas de paz que están abiertas a un ordenamiento espacial y temporal: i) las nociones energéticas de paz, que evocan la armonía en cuanto a que son paces que 
emergen en relaciones que están en equilibrio, alineando a los seres humanos, a la naturaleza y al cosmos; ii) las nociones morales de paz, que contrastan porque son paces que se originan en cosmovisiones donde prima la justicia sobre la armonía, paces que intentan alcanzar la paz luchando para que el bien triunfe sobre el mal, de allí que se centren con frecuencia en el valor de la justicia misma; iii) paces modernas, que se distancian de creencias religiosas porque intentan fundar la paz en la razón, vislumbrando la construcción de paz como una cuestión de manejo y resolución de conflictos por medio de mayores niveles de progreso, civilización, desarrollo y seguridad; iv) paces posmodernas, que descreen de las promesas de mejoramiento de los seres humanos al compás de cosmovisiones Eurocéntricas y, por rechazarlas, se embarcan en la búsqueda de paces culturalmente ancladas en realidades cambiantes, híbridas y locales.

Finalmente, Wolfgang Dietrich (2012) propone que la paz como proyecto social necesita de todas estas paces, de los valores mismos de la armonía, de la justicia, de la seguridad y de la verdad, pero que al combinarlos de manera holística no implican una superación sino una distorsiónen el sentido heideggeriano de verwinden. ${ }^{4}$ Esto da vida a lo que se ha llamado un concepto transracional de paz, puesto que integra la racionalidad de las ciencias modernas, junto con la espiritualidad y la aceptación de una pluralidad de verdades, que resultan de la misma contextualización de la paz.

En cada una de estas categorías de paz, la sexualidad y el género son comprendidas de forma diversa. En las paces energéticas, el principio de la Gran Unión de lo masculino y lo femenino expresa precisamente la paz misma, "tal como lo encontramos en taoísmo en la relación de Yiny Yang, en hinduismo como Shiva y Shakti, o en Vudú como Ayida y Dambahla. Las deidades gemelas Freyry Freya de los Vanir nórdicos representan directamente el antaño placer como principio de la fertilidad y de la paz; y Paxy Mars, antes de sus connotaciones imperiales, eran el símbolo femenino y masculino de la fertilidad, Pax en la agricultura, Mars en la ganadería. Los dos juntos daban como resultado la paz" (Dietrich, W., 2009, p. 7).

Las connotaciones de sexualidad y género en la categoría de paz moral, sin embargo, se distancian de nociones energéticas y, aunque lo femenino y lo masculino continúan siendo comprendidas dentro de una cosmovisión orgánica, comienzan a perfilarse como opuestos en una relación dualística. Un ejemplo de ello puede ser la reinterpretación de la Pax Romana, que toma su significado pre-imperial de Diosa de la Fertilidad y la convierte en la Diosa de la Paz del Imperio, que era venerada - junto con la Diosa de la Victoria - como Paz Romana de la Victoria (Dietrich, W., 2009, p. 10). En esta categoría, vemos cómo la paz se desprende de su carácter cambiante y contextual para convertirse en una paz normativa y de dominación. Mientras que en concepciones energéticas lo masculino y lo femenino se necesitan mutuamente para alcanzar un equilibrio dinámico, en la paz moral el triunfo de la justicia o de la norma es planteado como la instauración de la paz. La paz, pues, implica que los géneros también deben entenderse en una relación de dominación en la que la destrucción de lo opuesto es idealizada. La veneración de los Dioses en las religiones monoteístas, que caracterizan las paces morales, instauran además la idea de que lo masculino es aquello que debe prevalecer sobre lo femenino, puesto que de allí se confieren también los valores morales que deben regir el bien.

En un marco de paz moderna, donde prima la idea de un ser humano autónomo, razonable y separado de la naturaleza, género y sexualidad se presentan como cualidades inalienables del individuo. Al ser los hombres masculinos quienes se identificaron primordialmente con la idea de razón e individualidad, los géneros femeninos quedaron relegados a un segundo plano. La paz se entiende en la Modernidad como la 'paz del hombre', literalmente, pues tal género masculino tenía la capacidad de decidir no sólo las cuestiones filosóficas y científicas, sino también de organización social, política y económica que prometen paz. La sexualidad se percibe entonces como una función biológica a partir de necesidades físicas y de reproducción, negando sus connotaciones emocionales y espirituales.

4 "Verwindung es el término adoptado por Heidegger en lugar de Überwindung, de la superación característica de la dialéctica", hace alusión a la "caída distorsionante", y el "ponerse de nuevo", en el sentido de "reponerse de", "ponerse de nuevo a", y también en el de "proyectarse hacia el futuro". (Vattimo, 2006, p. 381). 
En un marco posmoderno de paces, géneros y sexualidad también invitan el plural mismo de esta filosofía. No se trata, como en la Modernidad, de encontrar la función de una posición binaria femenino/masculino, sino de comprender desde un ángulo perspectivista que los géneros se construyen a partir de interacciones sociales, y que las sexualidades - también en plural - hacen parte inextricable de la experimentación de la paz. Heterogeneidad y la falta de funcionalidad de los géneros y de las sexualidades traen consigo nociones de paz que no pretenden tener validez para todos y todas (como lo pretenden las modernas), sino que se suponen incompletas, inefables y temporales.

Viendo este amplio abanico de nociones de paz que propone W. Dietrich, se hace entonces imposible pensar en un solo método o una sola forma de transformación de conflictos. Si además reconocemos la estrechez de un concepto de racionalidad sin espiritualidad y por lo tanto nos embarcamos en el reconocimiento de las características Transracionales de paz, no queda otro camino que la apuesta elicitiva por la Transformación de conflictos. Este elemento lo tomamos prestado de John Paul Lederach $(1995,2003,2005)$, cuya experiencia como mediador lo llevó a postular que los métodos prescriptivos o "recetas", que prometen enviar entrenadores o expertos para resolver los problemas de los demás, poco funcionan en la práctica y, con frecuencias, dañan aún más las precarias relaciones en contextos conflictivos.

Lederach propone comprender los conflictos como "enredos" o pleitos relacionales que sólo pueden transformarse a partir de los saberes de las partes involucradas en el conflicto mismo. Para enfrentar estos conflictos una receta traída desde afuera puede llegar a ser una perturbación más. Lederach (1995, p. 65) formula un enfoque "elicitivo" o "evocador" que tiene como base la cultura y el contexto mismos en donde se asientan los conflictos, y en el que el mediador o entrenador actúa como un catalizador, más que como un experto. El trabajo de transformación elicitivo responde a principios como el respeto y la valoración de diferentes saberes (no sólo profesionales, sino también informales), y convoca a los participantes a em - y apoderarse de su situación al hacerlos activos también en la creación de modelos o estrategias de transformación que se validan y construyen en sus propios contextos.

La transformación elicitiva de conflictos implica entonces que sexualidades y géneros hacen parte de ese lecho del río, en el lenguaje metafórico de Lederach (1995), que no puede deslindarse o desvincularse de los conflictos, pues lo co-constituye. Esto implica que género y sexualidad no pueden añadirse como categoría a una situación conflictiva, sino que deben reconocerse cómo hilan (y en ocasiones enredan) las relaciones que nos vinculan a los seres humanos entre nosotros y también con la naturaleza y con el cosmos.

Al respecto, vale la pena entonces recordar que desde una perspectiva sistémica, a lo que le apuntamos es a comprender que, en el ir y venir de nuestras vidas, los conflictos son oportunidades en las que potencialmente podemos Transformar la relación y los sistemas mismos en que estas relaciones (de género y sexualidad, por ejemplo) están imbuidas (Lederach; Neufeldt; Culbertson, 2007, p. 17). Autores como Ludwig von Bertalanffy y Kenneth Boulding, entre otros, entienden como sistemas sociales, físicos y biológicos los que comparten los principios de resonancia, equilibrio dinámico y correspondencia (Dietrich, W., 2012, 2017). Esto lleva a los investigadores y trabajadores de paz a enfocarse no en modificar (mejorar, sanear o inclusive "asegurar") los elementos o participantes de los conflictos, sino a concentrarse en cómo cambiar las relaciones entre los elementos o participantes.

Nos orientamos para ello en las cuatro dimensiones de la transformación de Lederach, Neufeldt y Culbertson (2007): personal, relacional, estructural y cultural. Estas cuatro dimensiones de la transformación de los conflictos son "generadas", es decir, no necesitan que se incluya la categoría de manera adicional, sino que se constituyen a partir del género y de la sexualidad mismas. Género y sexualidad pueden entenderse en este contexto, en tanto los cambios que ocasionan y que son ocasionados por los conflictos cambian también a los individuos en sí mismos, en su sexualidad, emocionalidad y espiritualidad. Más allá de este aspecto personal, el género y la sexualidad también pueden entreverse en la dimensión 
relacional de la transformación en cuanto cuando los conflictos escalan, los patrones de comunicación cambian, y con frecuencia se (re)crean estereotipos de género que pueden incrementar la polarización y disminuir la confianza. Estructuralmente, los conflictos también impactan las instituciones y la manera en que las relaciones son organizadas socialmente, desde la familia hasta las comunidades y, por supuesto, tienen no sólo un carácter "generado", sino que también "generan" cambios de acceso en las relaciones de poder, por ejemplo. Finalmente, encontramos que en una dimensión cultural género y sexualidad también se asientan en normas y patrones de comportamiento "generadas", entre hombres y mujeres y otros géneros, por ejemplo.

\section{METODOLOGÍA}

Nos acercamos a las realidades conflictivas que, como investigadoras y trabajadoras de paz, nos afligen, y aparece una pregunta clave: ¿Cómo podemos operacionalizar estas ideas conceptuales y llevarlas a la práctica en situaciones concretas? Una respuesta la ofrece la propuesta metodológica del Mapeo Elicitivo de Conflictos (MEC) (Dietrich, W., 2017; Echavarría,2014; Organización de las Naciones Unidas para la Educación, la Ciencia y la Cultura, 2014). El MEC ofrece una ruta de análisis por el paisaje conflictivo, a manera metafórica, que se resume en la Figura 1, el mapa mental.

Figura 1: Mapa mental del mapeo elicitivo de conflictos (MEC)

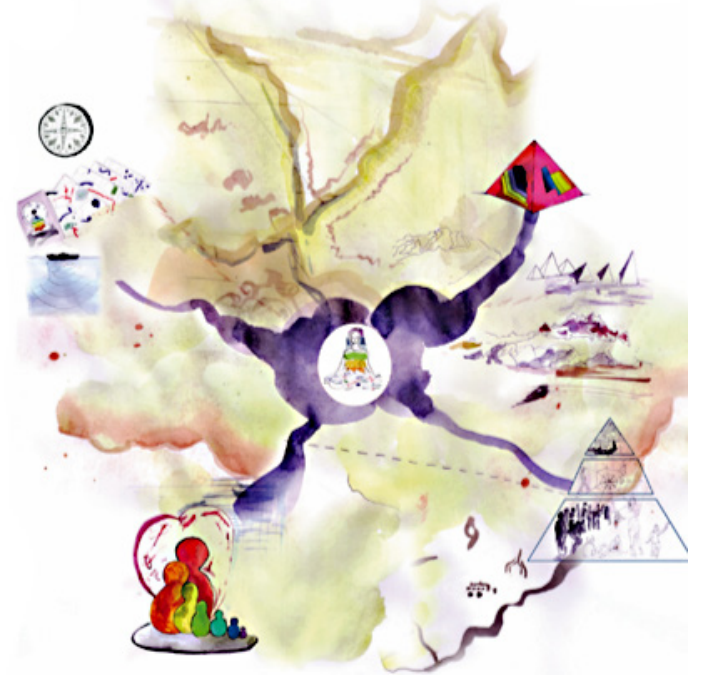

Fuente: Organización de las Naciones Unidas para la Educación, la Ciencia y la Cultura, 2014.

Este mapa contiene de manera simplificada las ideas principales sobre la filosofía de paz transracional y la transformación elicitiva de conflictos. Primero, en el centro encontramos al analista, investigador o mediador, que en general llamamos trabajadores de paz. Ellos se encuentran en el centro del paisaje conflictivo, lo cual marca esta aproximación sistémica que indica que los trabajadores de paz no son personas "ajenas" al conflicto, sino que, al involucrarse, también generan cambios en las relaciones entre los participantes. ${ }^{5}$

En el mapa mental MEC, en la rama superior izquierda, encontramos los principios elicitivos que ya se habían mencionado anteriormente: correspondencia, resonancia y equilibrio. En este volumen, Dietrich explica estos tres principios de manera

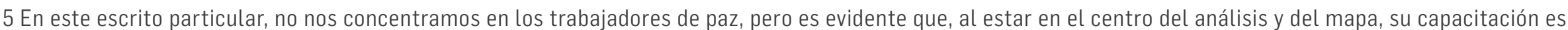

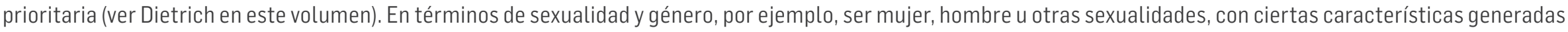

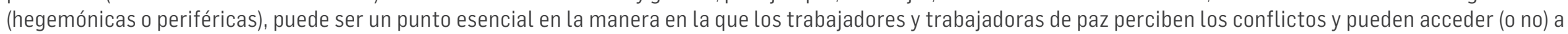

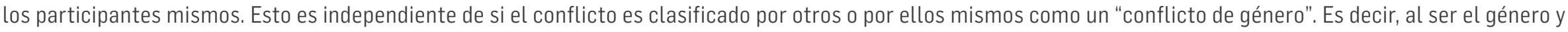
la sexualidad características y relaciones de las personas mismas, siempre están presentes en los conflictos. 
generosa. Al analizar un conflicto, estos principios han de estar al servicio de los trabajadores de paz a medida que avanzan en la identificación de un episodio conflictivo y del análisis del epicentro.

En la rama superior derecha vemos la pirámide de las familias de paz. Al compás de los principios elicitivos, los trabajadores de paz han de identificar en cada situación conflictiva cómo se relacionan entre sí las diferentes familias de paz. Esto implica no sólo estudiar las narrativas de los conflictos presentes en el episodio, pero ir más allá y preguntarse cómo tales narrativas revelan entendimientos de paz particulares, como paces energéticas, morales, modernas y/o posmodernas. Cuando una o dos categorías de paz dominan en los conflictos, tienden a perderse de vista las demás nociones de paz que - siguiendo la teoría transracional - están presentes en todos los contextos, con menor o mayor peso, pero siempre han de estar allí. Por ello, los trabajadores de paz intentan comprender aquel desbalance con miras a reequilibrarlo más adelante en la intervención.

En la rama inferior izquierda se encuentra la representación de las capas de la persona, que Dietrich comenta en este volumen (cf. Dietrich, W., 2017). A modo de representación de una matrioshka, o muñeca rusa, la persona se ilustra allí de forma metafórica en diversas capas que se superponen unas a otras. Siguiendo el principio tántrico de correspondencia, encontramos la primera capa sexual-familiar. Puede allí entreverse claramente la importancia de géneros y sexualidades, que influencian de manera directa los acontecimientos conflictivos, los estilos de comunicación de las partes involucradas y la capacidad de relacionarse de manera fluida consigo mismas y con las demás. Todos los participantes de un conflicto (así como los trabajadores de paz que los analizan) tienen además una familia de origen, bien sea con vínculos de sangre o de crianza, de la que han aprendido importantes estrategias de comportamiento, en las que la formación de las sexualidades es fundamental. La biografía sexual, a su vez, afecta la composición de la familia, y viceversa.

En las siguientes capas emocional-comunitarias, mental-societal y espiritual-policitaria, sexualidades y géneros también juegan un papel, aunque puede no entreverse de manera inmediata. Por ejemplo, los vínculos emocionales que se ubican en la capa comunitaria y emocional se crean y se recrean a partir de los lazos sexuales; las ideas sobre géneros y los roles de géneros, así como los conceptos sobre diferentes sexualidades afectan las instituciones societales; y finalmente los géneros y sexualidades también se inscriben dentro del sentido del yo que permite una percepción y experiencia del todo que se inscribe en la capa espiritual-policitaria. Géneros y sexualidades atraviesan los cuerpos, los corazones, las mentes y los espíritus de las partes en conflictos, afectan y son afectados por los conflictos mismos y, por lo tanto, son parte indispensable de cualquier análisis, aunque no siempre aparezcan en el foco de atención.

En la rama derecha inferior se hallan los actores y actrices de paz y conflictos, que se ubican a lo largo de diferentes niveles: en la cima, en el medio y en las bases, quienes, a pesar de su visualización metafórica en una simple pirámide, nos recuerdan nociones sistémicas en que todos los participantes ocupan, a su vez, no sólo la posición de 'su' nivel, sino que se encuentran imbuidos en sistemas más amplios en los que pueden estar en sub-niveles o sub-sistemas. Esta reinterpretación sistémica de los niveles (Dietrich, W., 2017; Lederach, 2005) pone de relieve los géneros y las sexualidades de manera explícita en cuanto se refieren a las personas implicadas en la realidad conflictiva, quienes no sólo viven, experimentan y perciben el conflicto de manera "generada", sino también quienes por sus géneros y sexualidades tienen capacidades diferenciadas para transformar los conflictos que los atañen. Las posiciones de víctimas y victimarios, así como las más complejas articulaciones en sobrevivientes, nos permiten ya una mirada más profunda de estos niveles, pero siempre nos dejan, en una aproximación elicitiva, la necesidad urgente de involucrarnos, escuchar y crear espacios de resonancia donde sus voces se escuchen de manera personal y relacional. De allí que los análisis "de escritorio" se desvanecen para darle paso a la interacción de los trabajadores de paz con los participantes directamente.

Precisamente haciendo eco de esta metodología de transformación elicitiva, se hace entonces imposible realizar un análisis MEC puramente documental desde los "escritorios", pues el contacto y la resonancia con personas directamente 
involucradas en los conflictos que estudiamos se vuelve indispensable para un análisis fresco, generado y des-seguritizado de los asesinatos de San Luis Talpa. Enmarcado dentro de una investigación doctoral más amplia en la Universidad Noruega de Ciencias para la Vida, para la realización del análisis MEC utilizamos discursos mediáticos sobre los acontecimientos violentos complementados con tres entrevistas semi-estructuradas y un grupo focal, realizado en San Salvador durante noviembre 2017 y enero 2018, con mujeres trans y activistas y defensoras de derechos humanos de la población LGBTI (lesbianas, gays, bisexuales, transexuales e intersexuales). Sus voces nos han ayudado a trazar un nuevo mapa conflictivo de los casos de violencia de San Luis Talpa.

\section{SAN LUIS TALPA BAJO LOS LENTES MEC}

Buscando entonces analizar el conflicto generado por el asesinato de tres mujeres trans en el departamento de La Paz, como un episodio violento que está conectado a patrones más profundos de valorización del ser humano y del uso estratégico de la violencia en la sociedad, es valioso emplear un método transracional de transformación de conflictos para entender el epicentro del conflicto. Con esta intención, la pregunta de investigación que guía este análisis es: ¿Qué revela el asesinato de tres mujeres trans sobre la sexualidad y el género en el epicentro de las violencias seguritizadas en El Salvador?Puntualmente, queremos preguntarnos, ¿cuáles son las miradas alternativas a este conflicto a la luz del MEC?

\section{Temas}

En la primera rama del MEC encontramos las diversas interpretaciones de paz. En este análisis particular nos preguntamos, ¿cuáles son las categorías de paz que están en desequilibrio? Buscamos indicios de tales categorías al escuchar atentamente las necesidades insatisfechas que las partes en conflicto expresan. Analizando el caso San Luis Talpa desde una perspectiva transracional, el episodio pone de relieve un conflicto entre dos niveles de aproximación a la paz, el del Estado y el de las organizaciones de base que defienden los derechos de las mujeres trans, incluyendo a las mujeres trans afectadas en este grupo como víctimas y sobrevivientes.

El Estado salvadoreño, por su parte, ha venido construyendo desde el final de la guerra civil su narrativa de paz a partir de la relación, no siempre armoniosa, entre justicia y seguridad ${ }^{6}$, en donde la definición de justicia se entrelaza con la moralidad cristiana, y la de seguridad sigue atada al Estado, a pesar de una reforma al sistema de seguridad y policial negociada dentro de los Acuerdos de Paz. Esto se puede ver en la incidencia de las iglesias (católica, cristiana y evangélicas) en la toma de decisiones políticas sobre el bienestar de la población, por ejemplo, sobre la salud sexual y reproductiva; la despenalización del aborto y la aprobación de cuatro causales ${ }^{7}$; o para la legislación de leyes que reconozcan los derechos de la población LGBTI (Comcavis; Aspid Arcoiris; Generación HT, 2015, p. 62; Dudley, 2000; Ramos, 2015, 86-87).

Adicionalmente, la aplicación de una lógica de seguritización como solución a la mayoría de los conflictos sociales ha marcado a los gobiernos del posconflicto. Esto ha traído a los gobiernos de derecha, ARENA, a implementar políticas de Mano Duray

\footnotetext{
6 Aunque esta narrativa de paz se podría remontar hasta su fundación como estado, especialmente cuando se estudia la relación del estado salvadoreño con la violencia y su legitimación simbólica (Hume, 2009a, p. 5-9). Lo que permite cuestionar la posibilidad de "transformación social" real planteada por un Acuerdo de Paz que no disputa la centralidad de la seguridad en la postguerra.

7 En el 2016 la diputada Lorena Peña del FMLN, apoyada por organizaciones de mujeres y la Agrupación Ciudadana contra la Despenalización del Aborto, propuso reformar el artículo 133 del código penal que penaliza totalmente el aborto, para despenalizarlo cuando se cumplan cuatro causales que atentan grave y directamente los derechos y la vida de la mujer. Estas son: "1) Para salvar la vida de la mujer gestante y preservar su salud, previo dictamen médico y con el conocimiento de la mujer; 2) El realizado por facultativo con consentimiento de la mujer, cuando sea un embarazo que fue producto de una violación sexual o trata de personas; 3 ) El realizado por facultativo, con consentimiento de la mujer cuando exista una malformación del feto que haga inviable la vida extrauterina; 4) El realizado por facultativo, con consentimiento de la menor de edad en los casos de violación y estupro, con autorización de sus padres o tutores legales, de acuerdo a lo establecido en el artículo 18 de la Ley de Protección Integral de la Niñez y Adolescencia (Lepina)" (El Salvador, 2016, p. 4).
} 
Súper Mano Dura; y a los gobiernos de izquierda, FMLN, a responder discursivamente de formas menos represivas, pero, aun así, el Gobierno de Salvador Sánchez Cerén (2014 - 2019) ha aplicado Medidas Extraordinarias de seguridad en las cárceles y seguritizado las políticas sociales a través de operaciones conjuntas entre policías y militares.

La seguritización articula el discurso sociopolítico y de gobernación (Amar, 2013, p. 27), y, en el caso de El Salvador, ha sido altamente efectivo en la perpetuación del arquetipo de inseguridad: lo que hoy son las pandillas, en otro tiempo fueron las guerrillas. Esta construcción se ha hecho con la intención de propiciar las condiciones para que los políticos usen las necesidades de seguridad de la población dentro de sus luchas de poder, sin el compromiso práctico de ofrecer alternativas de cambio.

\section{Seguridad soberana y relacional}

Al analizar el conflicto de San Luis recorriendo la rama de niveles o actores y actrices de paz y conflictos, encontramos en la base de la pirámide a las organizaciones locales de defensa de los DDHH, de las personas LGBTI y las mujeres Trans afectadas. Sus narrativas de paz expresan demandas de justicia social y seguridad, como el acceso a derechos ciudadanos y garantías de vida dignas que deben ser propiciadas por el Estado. Como expresaba Nahomy, una participante del grupo focal, cuando en el cierre de nuestra conversación sobre un lugar seguro, les pregunté ¿qué necesita uno como ser humano?

[...] uno necesita el reconocimiento legal para acceder, porque al reconocer legalmente a la persona hay mejores oportunidades de empleo, de estudios. Y que no la discriminen por ser una trans. Que sea reconocida y que haya libertad para emplear. (Nahomy, Grupo focal, San Salvador, 2018)

Mildred, otra participante del grupo focal, añadió lo siguiente en la discusión, aduciendo lo que le diría a los diputados y a la sociedad si tuvieran una visión diferente de las mujeres trans:

\footnotetext{
[...] mi objetivo no es quitarle sus creencias religiosas, o venir a invadir, o venir a imponerle el hecho de que yo sea respetada como una mujer trans. El hecho de que yo, tener un nombre porque con mi nombre - como mi expresión es femenina - yo pueda tener mejores oportunidades laborales. Vea, porque con el nombre y con las funciones que yo tengo, yo puedo ser una mujer muy útil ante la sociedad, de diferentes maneras. Pero existe esa parte que me limita a mí que, por mi nombre, según tú, yo no puedo tener trabajo digno, por muchos conocimientos que yo tenga. (Mildred, grupo focal, San Salvador 2018)
}

Estas demandas están atravesadas por necesidades de "armonía" y de "pluralidad de verdades", como el reconocimiento social y cultural de la identidad de género y orientación sexual de las personas, y la materialización de este reconocimiento en políticas de identidad diferenciada. Específicamente escuchamos la petición por una ley de identidad de género que permita a las personas trans ser reconocidas como ciudadanas y gozar de sus derechos. Tal insistencia se debe a la prohibición de cambiar el nombre en el documento único de identidad (DUI) si no concuerda con el sexo estipulado en la partida de nacimiento. Esta prohibición es una limitante para las personas trans, pues las pone en situaciones de riesgo - violencia psicológica, física, marginación - cada vez que su identidad debe ser corroborada con su identificación legal. Por ejemplo, al solicitar servicios de salud, bancarios, educativos; al movilizarse entre fronteras; al sufragar; entre otros.

Cuando nos aproximamos al episodio partiendo de la identificación de las demandas y necesidades insatisfechas en estos dos niveles de actuación, se revela que las categorías de paz del Estado están conectadas a nociones de paces morales y modernas (Dietrich, W., 2012), mientras que las necesidades de las mujeres Trans, aun cuando se expresan en términos de seguridad y justicia, están alineadas a nociones de paces energéticas y posmodernas (Dietrich, W., 2012). En este caso, las distintas posiciones y características de paces generan un desequilibro en el sistema que es necesario balancear para contrapesar la prevalencia de la lógica de seguridad y justicia por parte del Estado. 
El caso de San Luis Talpa pone de manifiesto la centralidad de la sexualidad y del género en las categorías de paz presentes en el episodio y su posible desequilibrio. Al analizar las necesidades de las personas afectadas, se entrevé un clamor por la justicia y la no impunidad. Al respecto, la activista de derechos humanos LGBTI, Biaka Rodríguez, comentaba que el caso de San Luis Talpa lo manejaba la policía como un caso de territorialización de las maras, porque a las mujeres las asesinaron en un lugar diferente al que ellas residían. Sin embargo, dice ella, ni los policías ni la fiscalía explican la intensión de los disparos contra estas mujeres trans. Asimismo, lo compara con el caso de Tania, ${ }^{8}$ una activista de derechos humanos LGBTI asesinada en 2014, porque la justicia aún no ha resuelto el crimen, y, aún después de confirmar la saña con la que fue causado, hasta el 2015, lo manejaba la fiscalía como un homicidio culposo, "[...] que ella se lo había buscado [...]" (Bianka, entrevista semi-estructurada, San Salvador, 2018).

Este episodio se conecta con un historial de necesidades no satisfechas expresadas en demandas de reconocimiento de la identidad de género. Sin embargo, esta demanda no es nueva. Las organizaciones defensoras de derechos humanos de la población LGBTI, COMCAVIS, ARCOIRIS y GENERACIÓN-HT, presentaron una lista de violaciones a derechos humanos de las personas transgénero en El Salvador ante las Oficinas del Alto Comisionado para los Derechos Humanos de las Naciones Unidas, a principios del 2015 (Comcavis; Aspid Arcoiris; Generación HT, 2015). La Asamblea Legislativa Salvadoreña, por su parte, decretó, en septiembre del mismo año, una reforma al artículo 129 del Código Procesal Penal en donde se tipifican los crímenes de odio por razón de identidad de género y sexual (El Salvador, 2015).

La justicia, en este caso, se concibe como la sanción judicial del crimen como un crimen de odio. Tal noción de justicia no es pues equivalente a aquella impartida por el Estado. De acuerdo con las cifras manejadas por las organizaciones LGBTI en El Salvador (Comcavis; Aspid Arcoiris; Generación HT, 2015; Human Rights First, 2016), desde finales de los años noventa más de 600 personas han sido víctimas de ataques y crímenes de odio, y hasta la fecha (2018) no ha habido ninguna condena por crímenes de odio contra esta comunidad. Según los registros presentados por la Fiscalía General de la República (FGR) a la Comisión Interamericana de Derechos Humanos (CIDH) en marzo del 2017, de los 109 casos que investiga sobre delitos cometidos contra personas LGBTI entre diciembre de 2014 y principios de marzo de 2017,12 ya han sido judicializados por amenaza, lesiones y homicidio agravado (Cidón Kiernan, 2017). Esto quiere decir que, aun cuando hay una tipificación específica por crímenes de odio en contra de la orientación sexual e identidad de una persona, no se ha generado una condena directa por este tipo de actuación. La falta de condenas por estos crímenes de odio envía un mensaje de impunidad y, al rehusarse el Estado a visibilizarlos como crímenes de odio, no contribuye a la reducción de los hechos de victimización de poblaciones vulnerables.

El caso San Luis Talpa es conocido por las autoridades que las mujeres Trans fueron asesinadas por su identidad de género y por movilizarse en territorios que les eran "prohibidos". Por esta razón y por otras amenazas recibidas, muchas otras mujeres Trans residentes de San Luis Talpa decidieron emigrar a México y Estados Unidos por temor a perder sus vidas?.

Por tanto, las víctimas demandan la sanción del crimen como un crimen promovido por el odio y la discriminación. La sanción como un crimen de odio supondría el reconocimiento de la diversidad entre la identidad de género de las personas y su identificación sexual de nacimiento. Sin embargo, caso el Estado decida sancionar el crimen como un homicidio agravado y sumarlo a la lista de homicidios, reforzando la lógica de necesidad de seguridad.

Al analizar este episodio desde una perspectiva transracional y acercándonos a los énfasis temáticos para entender la forma en que se expresan las familias de paz, entendemos que la mirada oficial al conflicto en El Salvador prioriza un marco

8 Para más información del caso de Tania, véase Cruz (2015).

9 Veáse Seis... (2017). 
interpretativo de paces morales y modernas, en donde la narrativa de la justicia se entrelaza con la narrativa de la seguridad, y se dejan desatendidas las necesidades de reconocimiento de identidad y pluralidad de géneros y sexual, asociados a nociones de paces energéticas y posmodernas.

De acuerdo con las entrevistas con organizaciones de mujeres y LGBTI en El Salvador, la seguridad en este país no es inclusiva y, como ya hemos mencionado anteriormente, no da cuenta de las diversas expresiones de violencia ni de las realidades diferenciadas en donde se experimentan. Por el contrario, las políticas de Mano Durísma han creado un marco donde algunos sujetos son despojados de su humanidad, en cuanto que sus vidas han sido negadas y sus muertes son desconectadas de sus realidades sociales. Por ejemplo, durante el 2017, la policía contabilizó 497 combates con las pandillas, de los cuales solo 64 presuntos pandilleros resultaron heridos, mientras que 391 resultaron muertos (Labrador, 2018). La mayoría de estos jóvenes proviene de comunidades empobrecidas donde la pertenencia a una pandilla se define más en relación al territorio que habitan que a su afiliación criminal a la misma, de manera que estas muertes permiten pensar en ejecuciones extrajudiciales. Alternativamente, se puede dar el ejemplo de los 1518 casos de feminicidio presentados entre enero de 2015 y junio 2017 que siguen en impunidad (Luna, 2017); o recordar los ya mencionados 600 casos de crímenes contra la población LGBTI en este país desde 1990. La realidad es que los "cuerpos", que en su mayoría inflan las estadísticas de muertes en El Salvador, provienen de comunidades con bajos ingresos, con alta exclusión estructural y ciclos de violencia normalizados a través de la fuerza represiva del Estado.

Para investigar estos eventos, en febrero de 2018, estuvo en El Salvador la Relatora Especial de Naciones Unidas sobre ejecuciones extrajudiciales, Agnes Callamard. En su informe, se mostró en desacuerdo con las medidas extraordinarias del actual gobierno puesto que apuntan a la deshumanización de las personas, refiriéndose especialmente a la condición de los detenidos en las cárceles de máxima seguridad. Sin embargo, dentro de su informe también se refirió a la existencia de un marco de comportamiento por parte del personal de seguridad que permite las ejecuciones extrajudiciales, así como poco control estatal, los prejuicios religiosos y misóginos, y altos niveles de impunidad que favorecen los feminicidios y la violencia contra la población LGBTI, especialmente las mujeres Trans (Callamard, 2018).

Podemos ver que hay un desequilibrio al interior de las ideas de justicia moral y seguridad moderna promulgadas por el Estado, y una demanda de parte de las organizaciones LGBTI por el reconocimiento de la importancia de la identidad de género y sexual en este caso. La necesidad de este reconocimiento abre nuevas posibilidades para aproximarnos al epicentro del conflicto y encontrar alternativas para su transformación.

\section{Reconocimiento e identidad como aproximaciones a la transformación de conflictos}

Siguiendo la lógica de la seguridad, al preguntar en un grupo focal con mujeres trans sobre sus fuentes de inseguridad, las respuestas revelaron un entendimiento de seguridad más holístico y complejo que aquel que permite el discurso del Estado. Para las mujeres trans la primera causa de inseguridad es la falta de reconocimiento, porque esta se traduce en inseguridad psicológica, inseguridad estructural (legal, socioeconómica y material), y por último en inseguridad física. La inseguridad entonces no está asociada únicamente a la criminalidad, sino a la carencia de garantías de ciudadanía y vida digna que, en un país violento, representan el primer factor de riesgo para las mujeres trans.

Las organizaciones LGBTI demandan el reconocimiento de la identidad de género y la diferencia. Estas demandas parten de ideas de armonía y pluralidad de verdades, que a su vez están conectadas en su aproximación teórica a nociones de paces energéticas y posmodernas (Dietrich, W., 2012), respectivamente, en donde se celebra la unión de lo masculino y lo femenino, y se entiende la construcción social y la pluralidad de los géneros y de las sexualidades y su importancia en la experimentación de la paz. En cuanto a las aproximaciones prácticas, las organizaciones LGBTI en El Salvador han venido demandando una 
"Ley de Identidad" que dé reconocimiento jurídico a las personas transgénero a partir del reconocimiento del derecho a un nombre que corresponda con la identidad de género.

De acuerdo con el Informe sobre la Situación de los Derechos Humanos de las Mujeres Trans en El Salvadorrealizado por PNUD y la PDDH, "las mujeres trans no disfrutan de sus derechos y libertades fundamentales, tanto a nivel de garantías legales como en la vida cotidiana" (Programa de las Naciones Unidas para el Desarrollo, 2015, p. 12). Las experiencias cotidianas de vulneración de derechos por la que pasan las mujeres se originan en la falta de reconocimiento del derecho a la identidad y del derecho al nombre, de esta vulneración devienen otros once derechos fundamentales vulnerados, entre los que se encuentran el derecho al trabajo, la educación, la salud, a la igualdad y la no discriminación, a la vida y la seguridad personal, a no ser detenido(a) arbitrariamente, entre otros (Programa de las Naciones Unidas para el Desarrollo, 2013).

Según Ambar Alfaro, coordinadora de la "Mesa Permanente por una Ley de Identidad de Género en El Salvador", el poco reconocimiento social de la población trans sumado a su inexistencia legal las lleva a una paradoja entre la exclusión y la visibilidad, que está matando a las mujeres trans. Para Alfaro (entrevista personal), las mujeres trans pagan los costos de su visibilidad a través de la exclusión social, que representa una transición entre la muerte social y la muerte física. Debido a que las mujeres trans transgreden las normas sociales heteronormativas, se ven excluidas de muchos espacios - como la educación y el trabajo, entre otros - y sexualizadas. Es aquí donde ocurre la muerte social, pues esos espacios se cierran en relación directa con la visibilidad de su identidad de género y las encasilla en una identidad sexualizada. Las mujeres trans son estigmatizadas como trabajadoras sexuales, lo cual añade otro nivel de exclusión y vulnerabilidad. Pero además de la circunscripción de las mujeres trans al trabajo sexual, se las conecta con drogadicción, violencia y criminalidad, por el estigma que genera el trabajo en la calle, aumentando sus riesgos de ser vulneradas físicamente, tanto por las pandillas, las fuerzas públicas de seguridad, como por la sociedad civil en general. Es pues una lógica perversa que entrelaza la muerte social con la muerte física, que se convierte en un círculo vicioso en donde ambas lógicas violentas se refuerzan unas a otras.

De allí que la importancia del derecho al nombre y la identidad radica en la posibilidad de disminuir las inseguridades cotidianas asociadas a la discriminación y a la violencia psicológica y física que enfrenta la mayoría de las personas LGBTI debido a su identidad de género o preferencia sexual, pero especialmente las personas trans. El reconocimiento legal es la puerta de entrada para que puedan ejercer plenamente su ciudadanía y el disfrute pleno de su identidad diversa.

El 22 de Marzo del 2018, la diputada Lorena Peña del FMLN presentó la propuesta de "Ley de identidad de género" como un proyecto de ley en la Asamblea Legislativa (Acan-EFE, 2018). La demanda de las organizaciones trans y LGBTI por el derecho a la identidad y al nombre supone el reconocimiento de la existencia de la pluralidad de identidades de género y sexuales y visibiliza la importancia de la sexualidad y del género en el disfrute de la ciudadanía y, podríamos añadir, en la experimentación de la paz.

Por tanto, desde una perspectiva transracional, el reconocimiento político de esta demanda ya implica un espacio para la transformación del conflicto porque reconoce la voz de las personas en conflicto y escucha sus necesidades, que son diversas. Abre entonces la posibilidad de entender la seguridad desde una perspectiva relacional, más humana, menos mecánica, menos moderna (Echavarría, 2018; Organización de las Naciones Unidas para la Educación, la Ciencia y la Cultura, 2014). Esta "distorsión" de la seguridad soberana hacia una seguridad relacional va de la mano de la justicia como un mecanismo basado en las necesidades actuales de la población, y no en suposiciones normativas o morales del "deber ser" sexuado.

Estamos a la espera de que esta propuesta de ley sea aprobada en el debate de la Asamblea Legislativa y sea sancionada como ley. Por el momento, el reconocimiento de la necesidad de armonizar identidad de género y nombre público con la legislación 
permite hablar de posibilidades de transformación del epicentro del conflicto en el caso San Luis Talpa. El trasfondo más profundo entonces añora y pide cambios estructurales que se entrelazan y refuerzan cambios relacionales. La visibilidad del espacio privado en la narrativa pública, como un espacio en conflicto y un espacio político, invita a la apreciación de diferentes tipos de violencia y niveles diferenciados de vulneración. La dicotomía público/privado tiende a desdibujarse porque cada vez se hace más difícil argüir que el caso San Luis Talpa se puede resolver con una sentencia por el asesinato de "hombres vestidos de mujer", justificando el caso como uno más que se suma a una ya alta tasa de homicidios en un país violento. Este caso se convierte en el asesinato de mujeres trans promovido como una forma de rechazo a su identidad de género. La inseguridad, desde el discurso público, está entonces tan relacionada con la vida privada de las personas como la transformación de conflictos lo está con el reconocimiento de la sexualidad y el género como parte fundamental de las relaciones humanas. La falta de reconocimiento de la diversidad sexual y de género puede entonces dar luces sobre conflictos más profundos de reconocimiento de la diferencia.

\section{Capas: sexualidad, comunidad, identidad y reconocimiento}

El interés de la metodología transracional es ahondar en las capas más profundas del episodio del conflicto para llegar al epicentro y poder entender el conflicto más allá de las expresiones visibles de violencia. Para tal fin, es importante sacar a relucir opciones para Transformar las relaciones conflictivas entre las personas, en diferentes niveles desde lo Transpersonal a lo interpersonal y lo estructural, que no han sido tenidos en cuenta. Otra de esas formas alternativas de entender el epicentro del conflicto es buscando analizar la resonancia entre el interior y el exterior de la persona, teniendo como principio, en este caso, la sexualidad y el género. Como lo explicamos anteriormente, podemos entender las capas que conforman a cada uno de los actores implicados - agrupados en este caso como comunidad LGBTI (muy específicamente las mujeres trans), pandilleros, policías, Estado - como las capas de una muñeca rusa. Usando la metáfora de la muñeca podemos hablar de niveles de relacionamiento invisibilizados en la sociedad, en los que la sexualidad y el género están en la base.

En El Salvador, la organización social y política se ha estructurado en torno a una masculinidad hegemónica y patriarcal. Esta masculinidad ha sido cimentada en un discurso de construcción de nación y del uso de la violencia. La normalización de la violencia se conecta a la naturalización de estructuras desiguales de poder que privilegian la formación social de los hombres y hacen de la violencia un elemento importante del comportamiento masculino (Hume, 2008). De esta manera, lo femenino queda subordinado y se presenta como opuesto de lo masculino, es decir, sumiso a su autoridad. En este orden de ideas, la sexualidad se entiende desde su función biológica y se legitima en razón de un ideal heteronormativo.

Si pensamos que la primera capa de la persona es la que relaciona el nivel sexual con el familiar y lo ponemos en el contexto salvadoreño, vemos que hay un conflicto. A la luz de las cifras que demuestran que el lugar más violento para las mujeres y la niñez es la casa (Organización de las Naciones Unidas, 2006) se hace comprensible (más no justificable) que, en su mayoría, las mujeres trans viven su primera y más fuerte experiencia de exclusión social, marginación y violencia con su propia familia. Se crea un conflicto entre la identidad de género y sexual en la persona y el "deber ser" de su identidad de género y sexual que se expresa en la relación con la familia.

Por un lado, desde un marco heteronormativo, las sexualidades diversas se convierten en destructoras del orden establecido y deben ser marginadas. Por otro lado, las familias enaltecen la llegada de "varones" a la casa, porque la construcción social del sexo masculino lo empodera social, económica y políticamente, pero también lo convierte en el responsable de proteger y alimentar (Barker; Greene, 2010). De manera que cuando una persona al nacer es identificada con el sexo masculino, pero en su proceso de formación identitario se reconoce a sí misma con el género femenino, se presentan diversos conflictos asociados a las expectativas heteronormativas inscritas al sexo y al género designado al nacer. En muchos casos, la primera reacción de la familia es la negación y desde una perspectiva misógina y machista, se hace uso de la violencia como herramienta 
"adoctrinadora" (Hume, 2009a, p. 118). Lo que está en el epicentro de esta relación violenta es el miedo a una expresión de "ser" diferente, no normada y para la que no se tienen expectativas, que se ve acentuada por la vergüenza al no encajar en el marco de género normado por ideas religiosas de familia y moral. Y es el repudio contra lo que se asocia con "el sexo débil", que a su vez es la justificación de la violencia contra las mujeres.

Esta relación problemática entre sexualidad y familia empalma, a su vez, con la siguiente capa mental-societal, porque las expectativas se construyen social y culturalmente como relaciones de género. Cuando la sociedad reivindica un marco masculinista, patriarcal y heteronormativo, basado en expectativas socioeconómicas y culturales del "deber ser" de los hombres y de las mujeres, está generando un tipo de violencia sobre todas las personas que no encajan dentro del prototipo por cuenta de su propio proceso de identidad de género y sexual, por ejemplo, las mujeres trans. Esta reivindicación también posibilita y legitima violencias sobre todos aquellos a quienes las estructuras económicas y sociales excluyen y marginan. En el caso de los hombres, las prácticas violentas se relacionan con una cultura que privilegia la masculinidad hegemónica y con estructuras desiguales y exclusiones socioeconómicas que emasculizan. La masculinidad está conectada a dinámicas de clase social (Theidon, 2009). De manera que, en contextos sociales violentos donde adicionalmente se presentan procesos de emasculinización económica, la forma más común para expresar la masculinidad es a partir de formas hiperbólicas haciendo uso de la violencia, por ejemplo, a partir del porte de armas (Theidon, 2009). La hiper-masculinización afecta, por ejemplo, a aquellos que de una u otra manera terminan haciéndose miembros de pandillas y usando la violencia como herramienta de empoderamiento.

Desde esta perspectiva, la violencia social y psicológica causada por el miedo a la diferencia, y la violencia física por la reificación de la masculinidad y la subordinación de la feminidad están relacionadas con la violencia de la imposición de una masculinidad hegemónica (Connell, 1995). Esto se traduce en la normalización de la violencia en el espacio privado, lo que la hace invisible en el discurso público y en la incapacidad de nombrarla, porque al nombrar se reconoce. Entonces, es la incapacidad de reconocer la diversidad de posibilidades de ser y la vergüenza al aceptar, desde los preceptos de la moral cristiana, que la sexualidad tiene diferentes expresiones sociales más allá de su función biológica (Comisión Interaméricana de Derechos Humanos, 2015).

Así, desde una idea de paz moral y moderna, la moral religiosa se relaciona con las otras capas más externas de la persona, como la espiritual -policitaria en la medida en que los valores cristianos de familia tradicional, como base estructural de la sociedad, se trasponen en la idea de ciudadano ejemplar. Esto refleja el impacto de la religión en la negativa política a siquiera discutir la posibilidad legal del matrimonio entre personas del mismo sexo, o la posibilidad de despenalizar el aborto al menos en las cuatro causales para proteger la integridad de la mujer, que supone la necesidad de preguntarse ¿qué tipo de vida se defiende?

De igual forma, la incapacidad de reconocer las muertes de mujeres trans y los feminicidios como acciones violentas inspiradas por conflictos generados a partir de la sexualidad y el género, no permite explorar cómo la negación de la sexualidad y la creencia en la superioridad de la masculinidad hacen parte del epicentro de los conflictos sociales en El Salvador. Por ejemplo, como el miedo a la diferencia y la desestabilización de un sistema binario, generan la necesidad de "normalizar", de controlar y de marginalizar la diferencia a través de la represión de la sexualidad, del delito y de la diferencia. Ver la importancia de la sexualidad en la configuración de las relaciones de poder nos permite entenderla también como una metáfora de cómo se perciben social y políticamente los grupos que no encajan socialmente dentro de estos roles normativos. En este sentido, la comunidad LGBTI no es el único grupo excluido; las personas indígenas y afrodescendientes, las mujeres y las personas con movilidad reducida hacen parte de los grupos estructuralmente marginados. En el contexto actual de guerra contra las pandillas, la juventud que vive en comunidades en situación de pobreza y con presencia de pandillas es uno de los grupos más estigmatizados (Reyna et al., 2017, p. 64). 
Finalmente, al esgrimir que "la homosexualidad es enemigo de la moral", en un país manejado por el miedo y la lógica de la seguritización, es fácil caer en la generalización y estereotipos que implican a los jóvenes como sinónimo de guerrilleros/pandilleros. Dentro de este marco de políticas de "mano dura", se ha cementado en el imaginario político la asociación del pandillero como el "enemigo común del buen ciudadano" (Hume, 2009b, p. 745). Este análisis por las ramas de los temas, niveles y capas del conflicto sugiere que lo que yace en el epicentro del episodio de violencia del caso San Luis Talpa se conecta con otros episodios de violencia dentro del contexto de "la guerra contra las pandillas", reflejo de una sociedad - como tantas en América Latina - que hace uso de la violencia como estrategia para domesticar lo desconocido con la ambición de dar una "resolución" final a los conflictos (cf. Dietrich, L., 2014). Para la buena fortuna de los investigadores para la paz, sabemos que los conflictos producidos por el miedo a la diferencia, la diversidad y la disidencia no pueden "resolverse" por los mismos medios violentos que los generan e impulsan.

\section{RESULTADOS}

\section{Equilibrando seguridad y justicia con armonía y verdades}

¿Qué dicen la sexualidad y el género del epicentro de las políticas de seguridad de El Salvador y qué alternativas a este discurso hay?

Analizar el caso San Luis Talpa desde una mirada transracional nos ha permitido pensar el conflicto en otros términos más allá del marco moderno y moral que nos encasilla en círculos de violencia y no nos permite ver las necesidades de las personas involucradas más allá del discurso de seguridad. El preguntarnos, entonces, por la incidencia de la sexualidad y el género en el epicentro de las políticas de seguridad, nos brinda una interpretación diferente de la realidad, que desde el epicentro cuestiona la mirada acusatoria y deshumanizadora del otro, y propone una mirada más generosa, más compasiva y humana.

Cuando analizamos la narrativa pública del caso encontramos que los temas que sobresalen son los de seguridad y justicia, y la respuesta que se les da es a partir de la represión y la cárcel. Ahora bien, las políticas represivas de seguridad parecen una forma de resolver las expresiones de violencia, inhibiéndolas, pero no presentan opciones para entender las raíces de esas violencias ni cómo transformarlas. La cárcel parece el lugar en el que a través de la privación de libertad como castigo se genera un proceso de transformación. Pero no es así, no en El Salvador, en donde las cárceles están asociadas al hacinamiento, la insalubridad, el abuso, y el aumento de la violencia. Retomando las palabras de Agnes Callamand, las medidas de seguridad no pueden justificar procesos de deshumanización de los detenidos (Callamard, 2018, p. 3). Al final, las medidas de seguridad tienen la intención de deshumanizar no sólo a los detenidos como reos del sistema penal, sino sus identidades como pandilleros. Y esta deshumanización se centra en la falta de reconocimiento de su vulnerabilidad como seres humanos y de sus derechos y garantías - así como de sus responsabilidades y deberes-como ciudadanos.

Volviendo al caso San Luis Talpa, la discusión sobre la preferencia de la justicia por juzgar el episodio como un homicidio agravado, en contra de juzgarlo como un crimen de odio, pone sobre el tapete el tipo de justicia que se busca. Si bien ambas opciones parecen seguir una lógica punitiva, el juzgamiento de un acto violento como un crimen de odio está atado al reconocimiento de la discriminación y de la violencia dirigida contra personas por razón de su género e identidad de género y sexual. A su vez, el reconocimiento de este tipo de violencia en sí mismo representa el reconocimiento de la existencia de la diversidad sexual.

¿Dónde se presenta, entonces, la posibilidad de transformación? Cuando analizamos el episodio desde la perspectiva de los grupos que lo sobreviven, podemos entender que hay narrativas alternativas a la seguridad y la justicia. Desde la perspectiva de los grupos LGBTI y las mujeres trans, lo que está en juego con la justicia es el reconocimiento de su existencia diferenciada, de su humanidad y de su ciudadanía completa. En sí mismo, este se presenta como un llamado a la inclusión que exige que 
veamos la seguridad desde otra perspectiva. Así como los estudios feministas críticos de seguridad que cuestionan la visión Estado-céntrica de la seguridad y proponen un acercamiento más integral, desde el nivel de la persona, a este concepto (Stern, 2001). Se abre entonces la posibilidad de equilibrar visiones monolíticas de seguridad y justicia, con las demandas de armonía personal y reconocimiento colectivo de la diversidad de realidades y necesidades. En pocas palabras, la posibilidad que se abre es la del reconocimiento de la vida del otro.

Cuando nos centramos en el nivel de la persona, esas demandas se hacen mucho más claras y vemos cómo la sexualidad y el género se convierten en metáforas de la vulnerabilidad y de la violencia que viven los grupos marginados en este país, entre estos, las juventudes, las mujeres cis-género y las mujeres trans.

Lo que nos dicen el análisis de las capas de la persona es que, desde un marco heteronormativo, las sexualidades diversas son el otro. Y desde entonces, la relación con el otro, con el diferente, se hace a través del desconocimiento que se expresa en miedo. Por cuenta de ese miedo a la diferencia es que muchas mujeres trans son marginalizadas cuando se hace visible que no encajan en los patrones normativos (Comisión Interamericana de Derechos Humanos, 2013; Programa de las Naciones Unidas para el Desarrollo, 2015). Ese miedo a la diferencia hace que la población LGBTI sufra constantemente de violencia psicológica en los centros educativos, en los lugares de trabajo, en la calle, etc. Al entender, entonces, que el miedo se constituye como un patrón sistémico que genera exclusión y vulnera al otro desde su nivel más personal, es fundamental entender también que al hacer parte del epicentro del conflicto está naturalizado, y eso lo hace invisible. Por tal razón no se habla de él, y este silencio no permite su reconocimiento.

Es por esta razón que volver a lo más básico, al nivel de la persona, resulta tan revelador para Transformar el conflicto. Porque entendemos que son seres humanos quienes han sido vulnerados y sus vidas han sido afectadas. Si en este caso se puede reconocer a partir de la "Ley de la Identidad" la existencia legal de las personas transgénero, se puede, así mismo, reconocer el daño que se les ha ocasionado. El reconocimiento tiene entonces la posibilidad de transformar los ciclos de violencia en la medida en que los visibiliza y les presta atención a las necesidades de los actores en conflicto.

Extendiendo, entonces, la metáfora del miedo al otro como parte estructuradora de las políticas de seguridad, proponemos a partir de este análisis la importancia del reconocimiento de la existencia de diversidad, la aceptación de la pluralidad, como parte fundamental de la transformación de conflictos.

\section{DISCUSIÓN Y CONCLUSIONES}

El contexto latinoamericano se encuentra gravitando en torno a políticas de seguridad que, auspiciadas por las estrategias de Estados Unidos, refuerzan los marcos interpretativos morales y modernos de seguritización.

Es por esta razón que en este espacio hemos querido abrir un marco de interpretación de muchas y variadas nociones de paces para apuntar hacia la necesidad del reconocimiento de la existencia del otro, de su vulnerabilidad, de sus necesidades, como una forma fundamental de transformar conflictos. El otro representa la diversidad sexual y de géneros, como en el caso de las mujeres trans. Pensamos que el proceso de otrorización que viven las mujeres trans en El Salvador nos ilumina en cuanto a las formas en que otros grupos son tratados social y políticamente. El análisis MEC de la sexualidad y del género abre nuevos horizontes para entender la intransigencia de las políticas de seguridad contra las juventudes, vistas como ese otro no conforme y disidente, y la deshumanización de todos aquellos que se relacionan con las pandillas. Queremos extender esta invitación a incluir voces usualmente silenciadas en el marco del conflicto y miradas alternativas que nos permitan superar ciclos de violencia de manera más sostenible y con menos dolor en nuestra sociedad. 


\section{REFERENCIAS}

ACAN-EFE. Qué es la "ley de identidad de género" propuesta en la Asamblea Legislativa por el FMLN. La Prensa Gráfica, San Salvador, 22 mar. 2018. Disponible en: <http://bit.ly/2LHs3kp>. Acceso en: 23 jul. 2018.

AMAR, Paul. The security archipelago: human-security states, sexuality politics, and the end of neoliberalism. Durham: Duke University Press, 2013.

BARKER, Gary; GREENE, Margaret E. Qué tienen que ver los hombres con esto? Reflexiones sobre la inclusión de los hombres y las masculinidades en las políticas públicas para promover la equidad de género. In: AGUAYA, Francisco; SADLER, Michelle (Eds.). Masculinidades y políticas públicas. involucrando hombres en la equidad de género. Santiago de Chile: Facultad de Ciencias Sociales de la Universidad de Chile, 2011. p. 23-49.

CALLAMARD, Agnes. Declaración final de misión en El Salvador. Nueva York: ACNUDH, 2018.

CIDÓN KIERNAN, Maria. El Salvador dice que investiga más de 100 casos de ataques contra LGBTI. Revista Factum, San Salvador, 22 mar. 2017. <http://bit.ly/2LdHqVJ>. Acceso en: 20 jul. 2018.

CLAVEL, Tristan. InSight Crime's 2017 homicide round-up. InsightCrime, Washington, 19 ene. 2018. Disponible en: <http://bit.ly/2LaJoGq>. Acceso en: 20 jul. 2018.

COMCAVIS; ASPID ARCOIRIS; GENERACIÓN HT. Violaciones de Derechos humanos de las personas transgénero en El Salvador. lista de cuestiones sometida a las Naciones Unidas Oficina del Alto Comisionado para los Derechos Humanos. Chicago: Hearland Alliance, 2015. Disponible en: <http://bit.ly/2vlAgyP>. Acceso en: 3 ago. 2018.

COMISIÓN INTERAMERICANA DE DERECHOS HUMANOS. Informe para la audiencia ante la Comisión Interamericana de Derechos Humanos sobre la situación de violencia contra la población de mujeres trans en El Salvador. San José: CIDH, 2013.

Violencia contra las personas lesbianas, gay, bisexuales, trans e intersexuales en América. San José: CIDH, 2015. Disponible en: http://www.oas.org/es/cidh/informes/pdfs/violenciapersonaslgbti.pdf Acceso en: 20 jul. 2018.

CONNELL, Raewyn W. The social organization of masculinity. Masculinities, Cambridge, p. 67-86, 1995.

CRUZ, Carlos. Sin justicia: a Tania Vásquez la mataron en El Salvador hace dos años. Sinetiquetas, [S.l.], 4 maio 2015. Disponible en: <http://bit.ly/2LjHgMz>. Acceso en: 23 jul. 2018.

DIAMOND, David. Theatre for living: the art and science of community-based dialogue. Oxford: Trafford Publishing, 2007.

DIETRICH, Luisa. La "compañera política": mujeres militantes y espacios de "agencia" en insurgencias latinoamericanas. Colombia Internacional, Bogotá, n. 80, p. 83-133, ene.-abril 2014.

DIETRICH, Wolfgang. La llamada a las paces transracionales: cátedra magistral dictada el 20 de abril de 2009 en la Universidad de los Andes en Mérida (Venezuela), dentro del marco del I Encuentro Internacional de Arte, Paz y Sustenibilidad. Mérida: Univerdidad de los Andes, 2009. 
Interpretations of peace in history and culture. London: Palgrave Macmillan, 2012.

Elicitive conflict mapping. London: Palgrave Macmillan, 2017.

DUDLEY, Deborah. Perseguidas. proceso político y legislación sobre aborto en El Salvador - Un análisis de derechos humanos. New York: CRLP, 2000.

ECHAVARRÍA, Josefina. In/Security in Colombia: writing political identities in the democratic security policy. Manchester: Manchester University Press, 2010.

. (Re)Imagining migration. Peace Review: A Journal of Social Justice, Oxford, v. 26, n. 2, p. 178-184, 2014. Edición especial "Migrants and Cultures of Hospitality".

Sexuality, security and migration: seeking elicitive clues in the analysis of the 2015 Cologne's Sylvesternacht. In: ECHAVARRÍA, Josefina; INGRUBER, Daniela; KOPPENSTEINER, Norbert (Eds.). Transrational resonances: echoes to the many peaces. Houndsmill: Palgrave Macmillan, 2018.

EL SALVADOR. Asamblea Legislativa. Decreto no 106, de 24 de septiembre de 2015. Diario Oficial, San Salvador, n. 174, t. 408. Disponible en: <http://bit.ly/2NwHLiN>. Acceso en: 20 jul. 2018.

. Asamblea Legislativa. Reforma 133-A, de 11 de octubre de 2016. Diario Oficial, San Salvador, 11 oct. 2016. Disponible en: <http://bit.ly/2AOw5Dh>. Acceso en: 23 jul. 2018.

GALTUNG, Johan. Der Preis der Modernisierung: Struktur und Kultur im Weltsystem. Wien: Promedia, 1997.

HUMAN RIGHTS FIRST. Violencia motivada por prejuicio contra las personas Igbt en El Salvador. Human Rights First, Nueva York, 2016. Disponible en: <https://bit.ly/2LGdvBH>. Acceso en: 20 jul. 2018.

HUME, Mo. The myths of violence: gender, conflict, and community in El Salvador. Latin American Perspectives, Thousand Oaks, n. 35, v. 162, p. 59-76, 2008. doi: 10.1177/0094582X08321957.

The politics of violence: gender, conflict and community in El Salvador. Oxford: Wiley-Blackwell, 2009a.

Researching the gendered silences of violence in El Salvador. IDS Bulletin, Brighton, n. 40, v. 3, p. 79-85, 2009b.

LABRADOR, Gabriel. La investigación de San Blas parecía sesgada y se llegó a una decisión ridícula. El Faro, San Salvador, 11 feb. 2018. Disponible en: <http://bit.ly/2NF2Mbb>. Acceso en: 23 jul. 2018.

LA RAíZ de la discriminación. 12'42". Revista Factum. YouTube. 2017. Disponible en: <http://bit.ly/2zWpPMN>. Acceso en: 20 jul. 2018.

LEDERACH, John Paul. Preparing for peace: conflict transformation across cultures. Syracuse: Syracuse University Press, 1995. The little book of conflict transformation. Intercourse: Good Books, 2003.

The moral imagination: the art and soul of building peace. Oxford: Oxford University Press, 2005. 
LEDERACH, John Paul; NEUFELDT, Reina; CULBERTSON, Hal. Reflective peacebuilding: a planning, monitoring, and learning toolkit. Mindanao: Joan B. Kroc Institute for International Peace Studies; University of Notre Dame; Catholic Relief Services Southeast, 2007.

LUNA, Stanley. 1,519 mujeres asesinadas y solo 258 condenas por feminicidio en dos años. ElSavador.com, San Salvador, 23 dic. 2017. Disponible en: <http://bit.ly/209nW2d>. Acceso en: 23 jul. 2018.

OBSERVATORIO DEL DERECHO HUMANO A LA ALIMENTACIÓN EN CENTROAMÉRICA. El Salvador: costo de la canasta básica alimentaria 2014-2015. ODHAC, San Salvador, 2014. Disponible en: <http://bit.ly/2LfZmyW>. Acceso en: 23 jul. 2018.

ORGANIZACIÓN DE NACIONES UNIDAS. Poner fin a la violencia contra la mujer: de las palabras a los hechos - Estudio del secretario general de Naciones Unidas. Nueva York: Naciones Unidas, 2006.

ORGANIZACIÓN DE LAS NACIONES UNIDAS PARA LA EDUCACIÓN, LA CIENCIA Y LA CULTURA. Cátedra de Estudios de Paz. Elicitive conflict mapping online. Innsbruck: Universidad de Innsbruck, 2014. Disponible en: <http://bit.ly/202zcgZ>. Acceso en: 20 jul. 2018.

PROGRAMA DE LAS NACIONES UNIDAS PARA EL DESARROLLO. Procuraduría de Derechos Humanos de El Salvador. Informe sobre la situación de los derechos humanos de las mujeres trans en El Salvador. San Salvador: PDDH, 2015. Disponible en: <http://bit.ly/2KPicb9>. Acceso en: 3 ago. 2018.

RAMOS, Silvina (Ed.). Investigación sobre aborto en Améria Latina y el Caribe: una agenda renovada para informar políticas públicas e incidencia. Lima: Promsex, 2015.

RED FEMINISTA FRENTE A LA VIOLENCIA CONTRA LAS MUJERES. Informe sobre la situación de violencia contra las mujeres 2015. San Salvador: RED-FEM, 2016.

REYNA, Verónica et al. Inseguridad y violencia en El Salvador. el impacto en los derechos de adolescentes y jóvenes del municipio de Mejican. San Salvador: SSPAS, 2017.

SEIS personas desplazadas hacia Norteamérica por asesinato de tres transexuales en la paz. La Prensa Gráfica, San Salvador, 1 mar. 2017. Disponible en: <http://bit.ly/2LiHOgQ>. Acceso en: 23 jul. 2018.

STERN, Maria. Naming in/security - Constructing identity: "Mayan-women" in Guatemala on the eve of "peace". Göteborg: Department of Peace and Development Research Göteborg University, 2001.

THEIDON, Kimberly. Reconstructing masculinities: the disarmament, demobilization, and reintegration of former combatants in Colombia. Human Rights Quarterly, Baltimore, n. 31, v. 1, p. 1-34, 2009. doi: 10.1353/hrq.0.0053.

VALENCIA, Roberto. Un alza del 26\% en los asesinatos torpedea el discurso del FMLN en materia de seguridad. El Faro, San Salvador, 1 mar. 2018. Disponible en: <http://bit.ly/2Lkry3T>. Acceso en: 23 jul. 2018.

VATTIMO, Gianni. Dialéctica, diferencia y pensamiento débil. In: DIETRICH, Wolfgang; ECHAVARRÍA, Josefina; KOPPENSTEINER, Norbert (Eds.). Schlüsseltexte der Friedensforschung. LIT: Wien; Münster: LIT, 2006. 
VELÁSQUEZ ESTRADA, Ruth Elizabeth. Grassroots peacemaking: the paradox of reconciliation in El Salvador. Social Justice, Oxford, n. 41, v. 3, p. 69-86, 2015.

ZULVER, Julia. High-risk feminism in El Salvador: women's mobilisation in violent times. Gender \& Development, Abingdon, n. 24, v. 2, p. 171-85, 2016. doi: 10.1080/13552074.2016.1200883.

Artículo recibido el 10.05.2018 y aprobado el 20.06.2018. 